\title{
Is there an association between diabetes and neck pain and lower back pain? Results of a population-based study
}

This article was published in the following Dove Press journal: Journal of Pain Research

\section{Rodrigo Jimenez-Garcia' José Luis del Barrio' Valentín Hernandez-Barrera' Javier de Miguel-Díez ${ }^{2}$ Isabel Jimenez-Trujillo' María Angeles Martinez-Huedo ${ }^{3}$ Ana Lopez-de-Andres'}

'Preventive Medicine and Public Health Teaching and Research Unit, Health Sciences Faculty, Universidad Rey Juan Carlos, Alcorcón, Madrid, Spain; ${ }^{2}$ Respiratory Department, Hospital General Universitario Gregorio Marañón, Facultad de Medicina, Universidad Complutense de Madrid (UCM), Instituto de Investigación Sanitaria Gregorio Marañón (IiSGM), Madrid, Spain; ${ }^{3}$ Preventive Medicine and Public Health, Unidad de Docencia, Hospital Universitario La Paz, Madrid, Spain
Correspondence: Rodrigo Jimenez-Garcia Preventive Medicine and Public Health Teaching and Research Unit, Health Sciences Faculty, Universidad Rey Juan Carlos, Avenida de Atenas s/n, 28922 Alcorcón, Madrid, Spain

$\mathrm{Tel}+34914888853$

Fax +34 9| 4888848

Email rodrigo.jimenez@urjc.es
Background: The objective of the study was to study the association between low back pain (LBP), neck pain (NP), and diabetes while controlling for many sociodemographic characteristics, comorbidities, and lifestyle variables. The study also aimed to identify which of these variables is independently associated with LBP and NP among diabetes sufferers.

Methods: A case-control study using data taken from the European Health Interview Surveys for Spain was conducted in 2009/2010 ( $n=22,188)$ and $2014(n=22,842)$. We selected subjects $\geq 40$ years of age. Diabetes status was self-reported. One non-diabetic control was matched by the year of survey, age, and sex for each diabetic case. The presence of LBP and NP was defined as the affirmative answer to both of the questions: "Have you suffered chronic LBP/NP over the last 12 months?" and "Has your physician confirmed the diagnosis?" Independent variables included demographic and socioeconomic characteristics, health status variables, lifestyles, and pain characteristics.

Results: The prevalence of NP (32.2\% vs $26.8 \%)$ and LBP (37.1\% vs 30.3\%) was significantly higher among those suffering from diabetes. Multivariable analysis showed that diabetes was associated with a 1.19 (95\% CI 1.04-1.36) and 1.20 (95\% CI 1.06-1.35) higher risk of NP and LBP. Among diabetic subjects, being female, concomitant mental or respiratory disorders, being obese, and physically inactive are variables associated with suffering from these pains. Those suffering NP had 8 times higher risk of reporting LBP than those without NP and the same association is found among those suffering from LBP.

Conclusion: The prevalence and intensity of NP and LBP are high among people with diabetes, affecting them significantly more than their age- and sex-matched non-diabetic controls. Specific preventive and educational strategies must be implemented to reduce the incidence, severity, and negative effect on the quality of NP and LBP among diabetic patients.

Keywords: low back pain, neck pain, diabetes, survey

\section{Introduction}

According to the Global Burden of Disease Study 2015, low back pain (LBP) and neck pain (NP) were the leading causes of disability in $2015 .{ }^{1} \mathrm{NP}$ and LBP cause a decline in the health status and have important economic costs that seriously affect the quality of the social and working lives of people who have these pains. ${ }^{1-4}$ The estimated 1-year prevalence for these pains in Spain ranges from $10 \%$ to $15 \%$ in the adult population. ${ }^{5,6}$

Experimental investigations have analyzed the relationships between diabetes mellitus (DM) with spinal diseases, showing that DM is associated with intervertebral disc (IVD) degeneration and lumbar spinal stenosis. ${ }^{7,8}$ 
Krein et $\mathrm{al}^{9}$ conducted a cross-sectional study of 993 patients with DM and found that $\sim 60 \%$ had chronic pain, defined as pain present most of the time for 6 months or more during the past year, and the most commonly reported pain location was the back $(60 \%)$. Furthermore, the presence of comorbid chronic pain and greater pain severity was both associated with poorer overall DM self-management and increased difficulty with certain self-care activities, such as exercising on a regular basis.

Markers of DM disease progression, such as increased duration of time with DM and increased levels of glycated hemoglobin (HbAlc), have been independently associated with the presence of chronic back pain, suggesting that uncontrolled DM may be a contributing factor to the development of chronic back pain. ${ }^{10}$

Ritzwoller et $\mathrm{al}^{11}$ demonstrated that the likelihood of an inpatient admission in the 2 years following the index back pain event increased by $102 \%$ (OR 2.02; 95\% CI 1.69-2.40) if the patient had DM. Furthermore, DM had the highest incremental cost estimate compared to other comorbidities.

Population-based studies have demonstrated the association of LBP with DM and found higher prevalence among those suffering from this disease after adjusting for known risk factors of LBP. ${ }^{12-15}$

Previous studies on the relationship between NP and DM have yielded inconclusive results. ${ }^{15-17}$ Some argue that LBP and DM may have a spurious association that can be explained by obesity, a confounding variable that is an established risk factor for type $2 \mathrm{DM} .{ }^{18} \mathrm{NP}$ is of particular interest in this debate because it is a non-weight bearing region and is thus less susceptible to symptoms caused by increased weight bearing. ${ }^{18}$

However, in addition to obesity, differences in the sociodemographic characteristics, coexisting physical and mental conditions, and lifestyles may explain the associations of DM with LBP and NP described by other authors. ${ }^{12-17}$

It is of interest to study the relationship between back pain and DM in part because it may enable better handling of the disorders and because it may give clues to the pathophysiology of back pain. ${ }^{9}$

In this investigation, we aimed to study the association between LBP, NP, and DM while controlling for many sociodemographic characteristics, comorbidities, and lifestyle variables. We also aimed to identify which of these variables is independently associated with LBP and NP among diabetes sufferers.

\section{Methods}

We conducted a case-control study using individualized data taken from the European Health Interview Surveys for Spain (EHSS) conducted in 2009/2010 $(n=22,188)$ and 2014 $(n=22,842)$. These surveys cover a representative sample of non-institutionalized adults (age 15 years or over) residing in main family dwellings (households) in Spain. Information was collected from home-based, computer-assisted, personal interviews conducted from April 2009 to March 2010 for the EHSS 2009/2010 and from January to December 2014 for the EHSS 2014. Details on the survey methodology can be found elsewhere. ${ }^{19,20}$ We selected subjects aged 40 years or over.

\section{Study variables}

To identify those with DM in our study, we included all subjects if they answered affirmatively to either of the following questions: "Has your doctor told you that you are currently suffering from diabetes?" and/or "Have you taken any medication to treat diabetes in the last 2 weeks?"

Subjects who answered "No" to these two questions were selected to create the control group. One control was matched by age, sex, and region of residence for each diabetic case. We matched the by region of residence because Spain is divided into 17 regions. Each region has its own health services organization and the EHSS collects a different sample for each of these regions proportional to its population. If more than one control for a case was found available, it was randomly selected.

Individuals were classified as LBP sufferers if they answered "Yes" to both of the following questions: "Have you suffered chronic pain in the lumbar region of your back over the last 12 months?" and "Has your physician confirmed the diagnosis?" Equivalent questions were used to identify those suffering from NP: "Have you suffered chronic pain in the cervical region of your back over the last 12 months?" and "Has your physician confirmed the diagnosis?" These definitions of variables have been used by our group in previous investigations. ${ }^{5}$

We analyzed the following independent variables:

1. Demographic and socioeconomic characteristics, including the following:

- Age: Categorized in four age groups "40-59 years", "60-69 years", "70-79 years", and "80 years or more".

- Sex: "Male" or "Female".

- Nationality: Collected with the question: "What is your country of birth?" with two options "Spain" or 
"Other country". It was codified as "Spanish born" and "Immigrant".

- Educational level: Collected with the question: "What is the highest education leaving certificate, diploma or education degree you have obtained?" with nine options "Don't know how to read or write", "Not finished primary education", "Only finished primary education", "Lower secondary education", "Upper secondary education" "Medium level professional grades", "Upper level professional grades" "University studies", and "Doctorate". Options 1-3 were considered "No studies/primary", options 4-6 were considered "Secondary education", and options 7-9 were considered "Higher education".

- Monthly income: Collected with the question "Can you please tell me which is the total monthly income you and the other members of your household receive? Collected as a continuous variable and categorized in " $<850 €$ ", "850-1,400 €" and ">1,400 €".

- Living with a partner: Collected with the question "Are you living with someone in this household as a couple?" Two possible options were "Yes" or "No".

2. Health status variables, including the following:

- Self-perceived health: Collected with the question "How is your health in general? Is it..." giving five options "Very good", "Good", "Fair", "Poor" and "Very poor". Categorized as "Very good/good" vs "Fair/poor/very poor".

- Self-reported physician diagnosed chronic conditions: "Respiratory diseases" (asthma, COPD, and emphysema); "heart diseases" (coronary disease, myocardial infarction, and angina); "Stroke" (cerebral infarction, cerebral hemorrhage, and cerebral embolism); "Mental disorder" (anxiety and depression); "High blood pressure" and "Cancer". Subjects were considered as sufferers of these conditions if they answered affirmatively to both of the following questions regarding that specific disease: "Do you have or have you ever had ......?" And "Was this disease/condition diagnosed by a medical doctor?".

3. Lifestyles, including the following:

- Self-reported body mass index (BMI): Collected with the questions "Could you tell me your height without shoes?" and "Could you tell me your weight without shoes and clothes?" These were collected as continuous variables, calculated, and categorized into " $<25$ ", "25-29.9", and " $\geq 30 " \mathrm{~kg} / \mathrm{m}^{2}$.

- Physical exercise: Collected using the question "Over the last 7 days, how many times you have been walking for at least 10 minutes?" It was categorized into "0-3 days" and "4-7 days".

- Tobacco use: Collected using the question "Do you smoke actually?" with four options "Yes, daily", "Yes, but not daily", "Not actually but I have smoked in the past", and "Not now or in the past". This variable was categorized into "Current smoker" options 1 and 2, "Exsmoker" option 3, and "Never" option 4.

- Alcohol consumption: Collected using the question "During the past 12 months, how often have you had an alcoholic drink of any kind (that is beer, wine, spirits, liqueurs or other alcoholic beverages)?" with six options "Never", "Monthly or less", "2-4 times a month", "2-3 times a week", "4-6 times a week", and "Every day". This variable was categorized into "No" options 1 and 2 and "Yes" option 3-6.

4. Pain characteristics, including the following:

- Pain intensity: Collected using the question "Overall, during the past 4 weeks, how much physical pain or physical discomfort did you experience?" with four options "Light", "Moderate", "Intense", and "Extreme". We re-codified into three categories "Light", "Moderate", and "Intense/extreme".

- Use of prescribed drugs for pain: Collected using the question "During the past 2 weeks, have you used any medicines for pain in the neck or back that were prescribed or recommended for you by a doctor?" with two options "Yes" and "No".

The questions used were identical in the two surveys used in our investigation. ${ }^{5,19-21}$

\section{Statistical analysis}

The distribution according to the study variables was described and compared for the diabetic and non-diabetic matched samples. We used proportions and means with SD as descriptive statistics. We estimated the prevalence of LBP and NP for subjects with and without DM.

Bivariate conditional logistic regression models were conducted to compare the distribution and prevalence between DM sufferers and their age-sex-matched controls according to study variables.

The chi-square test was used to analyze the association of the study variables with the different pain localizations among DM sufferers.

To assess the association of DM with the studied pain, we conducted two multivariable conditional logistic regression models. The dependent variable was "diabetes yes/no" 
and the main independent variables were the presence of the studied pains.

Finally, we identified the study variables that were independently associated with LBP and NP among subjects with DM. To do this, we constructed three multivariable unconditional logistic regression models.

The multivariable analyses were performed including those variables that were statistically significant in the bivariate analysis and those which, although they did not reach the point of statistical significance, were of interest from an epidemiological and healthcare point of view. The results of the regression models are shown as ORs with 95\% CIs. We checked for interactions in the models.

Matching and estimations were made using the STATA program, and statistical significance was set at two-tailed $\alpha<0.05$.

\section{Ethical aspects}

This study was conducted using an anonymous public access dataset, and confidentiality was maintained at all times. In accordance with Spanish legislation, it is not necessary to obtain the approval of an ethics committee.

\section{Results}

The prevalence of DM among subjects aged 40 years or over was $11.4 \%(1,704)$ for the EHSS 2009 and $11.7 \%(1,876)$ for the EHSS 2014.

Before matching was conducted, the mean age for the diabetic population was 69.6 years (SD 11.6) and it was 60.4 years (SD 13.7) among those without the disease $(p<0.001)$. The sex distributions were 53.1\% $(1,902)$ and $56.0 \%(15,310)$ females for those with and without DM, respectively $(p<0.001)$.

We matched a total of 3,441 diabetic subjects with age and sex controls, representing $95.7 \%$ of the diabetic subjects included in the EHSS 2009 and EHSS 2014.

The distribution of the study populations according to the demographic and socioeconomic variables, health status, lifestyles, and pain characteristics are shown in Table 1.

Subjects with DM had a significantly lower educational level and monthly income than their age-sex matched nondiabetic controls.

Self-reported health and all analyzed chronic conditions showed worse prevalence among the diabetic group. The prevalence rates of obesity $\left(\mathrm{BMI} \geq 30 \mathrm{~kg} / \mathrm{m}^{2}\right.$ ) were $35.1 \%$ and $21.3 \%$ for those with and without DM, respectively $(p<0.001)$. No differences were found for tobacco use, and diabetic subjects had significantly lower figures of physical exercise and alcohol consumption.

Regarding the pain intensity in the last 4 weeks, diabetic subjects reported "Light" 28.5\%, "Moderate" 37.2\%, and "Intense/extreme" $34.3 \%$ with the corresponding rates for the non-diabetic controls of $34.4 \%, 38.7 \%$, and $26.9 \%$, respectively $(p=0.01)$

DM sufferers had consumed prescribed pain medication in the last 2 weeks at a $9.4 \%$ higher proportion than their matched controls (47.9\% vs 38.5\%; $p<0.001)$.

The prevalence of pain in both the studied locations was significantly higher among those with DM than their age and sex-matched non-diabetic controls. For NP, the figures were $32.2 \%$ vs $26.8 \%$ and for LBP the figures were $37.1 \%$ vs $30.3 \%$. The corresponding crude ORs were 1.34 (95\% CI 1.20-1.50) and 1.38 (95\% CI 1.25-1.53), respectively.

The prevalence of simultaneous NP and LBP was higher among DM sufferers than among non-DM sufferers (16.8\% vs $14 \%, p<0.001)$.

Table 2 shows the prevalence of NP and LBP among diabetic subjects and non-diabetic controls according to study variables.

For the two pain locations, and beyond the DM status, the highest prevalence was found in the 70- to 79-year age group. Women had higher values than men, and the prevalence increased as the educational level decreased.

NP and LBP were significantly more prevalent among DM sufferers than among non-sufferers in most studied age groups in either sex and in those in the "No studies/primary" educational level category.

Regarding self-reported health, in addition to the DM status, those with "Fair/poor/very poor" health had approximately three times more pain in any location than those with "Very good/good" self-rated health.

As expected, those suffering from any of the chronic conditions had a higher prevalence of NP and LBP than those without these diseases. This occurs among diabetic and nondiabetic subjects. People with DM and mental disorders had a higher prevalence of NP (53.4\% vs $26.1 \%)$ and LBP $(59.8$ vs $30.6 \%$ ) than those with DM who were not suffering from these disorders $(p<0.05)$.

NP was significantly more frequent among DM sufferers than among DM subjects who did not have respiratory disease, heart disease, stroke, cancer, or mental disorders. No significant differences were found for those with any of these conditions. 
Table I Distribution of the study populations according to demographic and socioeconomic variables, health status, lifestyles, and pain characteristics

\begin{tabular}{|c|c|c|c|c|}
\hline Variable & Category & Diabetes N (\%) & No diabetes $\mathbf{N}(\%)$ & $p$-value \\
\hline \multirow[t]{4}{*}{ Age groups } & $40-59$ years & $743(21.6)$ & $743(21.6)$ & NA \\
\hline & $60-69$ years & $923(26.8)$ & $923(26.8)$ & \\
\hline & 70-79 years & $1,076(31.3)$ & $\mathrm{I}, 076(31.3)$ & \\
\hline & 80 or more & $699(20.3)$ & $699(20.3)$ & \\
\hline Sex & Female & I,843 (53.6) & $\mathrm{I}, 843(53.6)$ & NA \\
\hline Nationality & Immigrant & $68(2)$ & $83(2.4)$ & 0.214 \\
\hline \multirow[t]{3}{*}{ Educational level } & No studies/primary & $2,488(72.3)$ & $2,27 I(66)$ & 0.001 \\
\hline & Secondary & $665(19.3)$ & $696(20.2)$ & \\
\hline & High education & $288(8.4)$ & $474(13.8)$ & \\
\hline \multirow[t]{3}{*}{ Monthly income } & $<850 €$ & $\mathrm{I}, 198(4 \mathrm{I} .2)$ & $990(35.1)$ & 0.015 \\
\hline & $850-1,400 €$ & $789(27.1)$ & $734(26)$ & \\
\hline & $>1,400 €$ & $920(31.6)$ & I,097 (38.9) & \\
\hline Living with a partner & Yes & $1,921(55.8)$ & I,990 (57.8) & 0.068 \\
\hline Self-rated health & Fair/poor/very poor & $2,384(69.3)$ & $\mathrm{I}, 65 \mathrm{I}(48)$ & $<0.001$ \\
\hline Respiratory disease $\mathrm{a}^{\mathrm{a}}$ & Yes & $575(16.7)$ & $416(12.1)$ & $<0.001$ \\
\hline Heart disease $^{\mathrm{b}}$ & Yes & $856(24.9)$ & $505(14.7)$ & $<0.001$ \\
\hline Stroke & Yes & $205(6)$ & $113(3.3)$ & $<0.001$ \\
\hline High blood pressure & Yes & $2,166(62.9)$ & $\mathrm{I}, 485(43.2)$ & $<0.001$ \\
\hline Cancer & Yes & $260(7.6)$ & $196(5.7)$ & 0.002 \\
\hline Mental disorders ${ }^{d}$ & Yes & $77 \mid(22.4)$ & $574(16.7)$ & $<0.001$ \\
\hline \multirow[t]{3}{*}{ Body mass index } & $<25 \mathrm{~kg} / \mathrm{m}^{2}$ & $678(22.2)$ & I,059 (34.I) & $<0.001$ \\
\hline & $25-29.9 \mathrm{~kg} / \mathrm{m}^{2}$ & $1,300(42.6)$ & $\mathrm{I}, 383(44.6)$ & \\
\hline & $\geq 30 \mathrm{~kg} / \mathrm{m}^{2}$ & I,07I (35.I) & $661(21.3)$ & \\
\hline Physical exercise ${ }^{e}$ & $0-3$ days & $1,335(38.8)$ & $\mathrm{I}, 194(34.7)$ & $<0.001$ \\
\hline \multirow[t]{3}{*}{ Tobacco use } & Current smoker & $477(14.4)$ & $499(15)$ & 0.746 \\
\hline & Ex-smoker & $981(29.6)$ & $921(27.7)$ & \\
\hline & Never & $\mathrm{I}, 854(56)$ & $\mathrm{I}, 90 \mathrm{I}(57.2)$ & \\
\hline Alcohol consumption ${ }^{f}$ & Yes & $\mathrm{I}, 008(29.3)$ & $\mathrm{I}, 404(40.8)$ & $<0.001$ \\
\hline \multirow[t]{3}{*}{ Pain intensitys } & Light & $606(28.5)$ & $633(34.4)$ & 0.010 \\
\hline & Moderate & $790(37.2)$ & $712(38.7)$ & \\
\hline & Intense/extreme & $728(34.3)$ & $496(26.9)$ & \\
\hline Use of pain medication ${ }^{\mathrm{h}}$ & Yes & I,649 (47.9) & $\mathrm{I}, 325(38.5)$ & $<0.001$ \\
\hline Neck pain & Yes & $1,109(32.2)$ & $921(26.8)$ & $<0.001$ \\
\hline Low back pain & Yes & $1,277(37.1)$ & $\mathrm{I}, 04 \mathrm{I}(30.3)$ & $<0.001$ \\
\hline Neck and low back pain & Yes & $579(16.8)$ & $482(14.0)$ & 0.001 \\
\hline
\end{tabular}

Notes: NA, because these are the matching variables. ${ }^{a}$ Respiratory diseases included asthma, COPD, and emphysema. ${ }^{b} \mathrm{Heart}$ disease included coronary disease, myocardial infarction, and angina. 'Stroke included cerebral infarction, cerebral hemorrhage, and cerebral embolism. Mental disorder included anxiety and depression. ePhysical exercise: days per week with walking for at least 10 minutes. ${ }^{\mathrm{f}} \mathrm{Alcohol}$ consumption: if the subject has consumed alcohol two or more times a month over the last year. ${ }^{\mathrm{g} P a i n}$ intensity

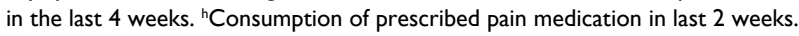

Abbreviation: NA, not applicable.

The prevalence of LBP was significantly higher among DM sufferers than among non-sufferers in addition to the category of self-rated health and if the subjects did or did not suffer from high blood pressure and mental disorders. For the NP, a higher prevalence was also significant for those not suffering from respiratory disease, heart disease, stroke, or cancer.

The prevalence of all pains increased with BMI among diabetic and non-diabetic subjects. Among diabetic and obese subjects, the prevalence rates of NP and LBP were $35.1 \%$ and $43.6 \%$ compared with $26 \%$ and $29.5 \%$ among those diabetic subjects with a BMI under $25 \mathrm{~kg} / \mathrm{m}^{2}(p<0.05)$.
Subjects with and without DM who walked for at least 10 minutes 4 or more days a week had lower prevalence of pain than sedentary persons.

The prevalence of NP and LBP were higher among never smokers and alcohol consumers in both study populations.

People with and without DM, reporting they were suffering "Severe/extreme" pain in the last 4 weeks and had used prescription pain medication, had a significantly higher prevalence of both pain localizations.

When we compared the prevalence of NP and LBP between diabetic subjects and their matched controls according to the categories of the lifestyle variables, we found a 
Table 2 Prevalence of neck pain and low back pain among diabetic subjects and age- and sex-matched non-diabetic controls according to study variables

\begin{tabular}{|c|c|c|c|c|c|}
\hline & & \multicolumn{2}{|l|}{ Neck pain } & \multicolumn{2}{|c|}{ Low back pain, n (\%) } \\
\hline & & $\begin{array}{l}\text { Diabetes } \\
\text { sufferer }\end{array}$ & $\begin{array}{l}\text { Non-diabetes } \\
\text { sufferer }\end{array}$ & $\begin{array}{l}\text { Diabetes } \\
\text { sufferer }\end{array}$ & $\begin{array}{l}\text { Non-diabetes } \\
\text { sufferer }\end{array}$ \\
\hline \multirow[t]{4}{*}{ Age groups ${ }^{c, d}$} & 40-59 years $^{\mathrm{a}, \mathrm{b}}$ & $203(27.3)$ & I48 (19.9) & 239 (32.2) & $183(24.6)$ \\
\hline & $60-69$ years $^{\mathrm{a}, \mathrm{b}}$ & $290(31.4)$ & $24 I(26.1)$ & $349(37.8)$ & $264(28.6)$ \\
\hline & $70-79$ years $^{\mathrm{a}}$ & $395(36.7)$ & $335(31.1)$ & 408 (37.9) & 365 (33.9) \\
\hline & 80 or more ${ }^{b}$ & $221(31.6)$ & $197(28.2)$ & $28 I(40.2)$ & $229(32.8)$ \\
\hline \multirow[t]{2}{*}{ Sex $x^{c, d}$} & $\mathrm{Male}^{\mathrm{a}, \mathrm{b}}$ & $335(2 \mathrm{I})$ & $260(16.3)$ & $443(27.7)$ & $354(22.2)$ \\
\hline & Female $^{\mathrm{a}, \mathrm{b}}$ & $774(42)$ & 661 (35.9) & $834(45.3)$ & $687(37.3)$ \\
\hline \multirow[t]{2}{*}{ Nationality $c, d$} & Spanish born ${ }^{\mathrm{a}, \mathrm{b}}$ & $1,098(32.6)$ & $910(27.1)$ & $1,261(37.4)$ & $\mathrm{I}, 024(30.5)$ \\
\hline & Immigrant & $11(16.2)$ & II (I3.3) & $16(23.5)$ & $17(20.5)$ \\
\hline \multirow[t]{3}{*}{ Educational level $l^{c, d}$} & No studies/primary ${ }^{\mathrm{a}, \mathrm{b}}$ & 881 (35.4) & $710(31.3)$ & $994(40)$ & $786(34.6)$ \\
\hline & Secondary & $175(26.3)$ & $150(2 \mid .6)$ & $211(31.7)$ & $183(26.3)$ \\
\hline & High education & $53(18.4)$ & $61(12.9)$ & $72(25)$ & $72(I 5.2)$ \\
\hline \multirow[t]{3}{*}{ Monthly income $e^{c, d}$} & $<850 €$ & $426(35.6)$ & $306(30.9)$ & $493(4 I .2)$ & $344(34.7)$ \\
\hline & $850-1,400 €$ & $278(35.2)$ & $233(31.7)$ & $30 I(38.1)$ & $270(36.8)$ \\
\hline & $>1,400 €^{\mathrm{a}, \mathrm{b}}$ & $264(28.7)$ & $252(23)$ & $300(32.6)$ & $276(25.2)$ \\
\hline \multirow[t]{2}{*}{ Living with a partner } & Yes $^{\mathrm{b}}$ & $613(31.9)$ & $488(24.5)$ & $699(36.4)$ & $573(28.8)$ \\
\hline & $\mathrm{No}^{\mathrm{a}, \mathrm{b}}$ & $496(32.6)$ & $433(29.8)$ & $578(38)$ & $468(32.3)$ \\
\hline \multirow[t]{2}{*}{ Self-rated health } & Very good/good & I47 (|3.9) & $216(12.1)$ & $179(16.9)$ & $279(\mid 5.6)$ \\
\hline & Fair/poor/very poor ${ }^{b}$ & $962(40.4)$ & $705(42.7)$ & I,098 (46.I) & $762(46.2)$ \\
\hline \multirow[t]{2}{*}{ Respiratory disease $\mathrm{e}^{\mathrm{c}, \mathrm{d}}$} & $\mathrm{No}^{\mathrm{a}, \mathrm{b}}$ & $848(29.6)$ & $759(25.1)$ & $974(34)$ & $862(28.5)$ \\
\hline & Yes & $26 \mathrm{I}(45.4)$ & $162(38.9)$ & $303(52.7)$ & $179(43)$ \\
\hline \multirow[t]{2}{*}{ Heart disease $e^{c, d}$} & $\mathrm{No}^{\mathrm{a}, \mathrm{b}}$ & $765(29.6)$ & $74 \mid(25.2)$ & $875(33.8)$ & $842(28.7)$ \\
\hline & Yes & $344(40.2)$ & $180(35.6)$ & $402(47)$ & $199(39.4)$ \\
\hline \multirow[t]{2}{*}{ Stroke } & $\mathrm{No}^{\mathrm{a}, \mathrm{b}}$ & $|, 04|(32.2)$ & $883(26.5)$ & $1,203(37.2)$ & $\mathrm{I}, 003(30.1)$ \\
\hline & Yes & $68(33.2)$ & $38(33.6)$ & $74(36.1)$ & $38(33.6)$ \\
\hline \multirow[t]{2}{*}{ High blood pressure ${ }^{c, d}$} & $\mathrm{No}^{\mathrm{b}}$ & $324(25.4)$ & $422(21.6)$ & $383(30)$ & $504(25.8)$ \\
\hline & $Y_{e s}^{b}$ & $785(36.2)$ & $499(33.6)$ & $894(4 \mid .3)$ & $537(36.2)$ \\
\hline \multirow[t]{2}{*}{ Cancer } & $\mathrm{No}^{\mathrm{a}-\mathrm{c}}$ & $1,013(31.8)$ & $849(26.2)$ & $1,171(36.8)$ & $961(29.6)$ \\
\hline & Yes & $96(36.9)$ & $72(36.7)$ & $106(40.8)$ & $80(40.8)$ \\
\hline \multirow[t]{2}{*}{ Mental disorders ${ }^{c, d}$} & $\mathrm{No}^{\mathrm{a}, \mathrm{b}}$ & $697(26.1)$ & $625(21.8)$ & $816(30.6)$ & $727(25.4)$ \\
\hline & Yes $^{\mathrm{b}}$ & $412(53.4)$ & $296(51.6)$ & $46 \mid(59.8)$ & $314(54.7)$ \\
\hline \multirow[t]{3}{*}{ Body mass index ${ }^{c, d}$} & $<25 \mathrm{~kg} / \mathrm{m}^{2}$ & $176(26)$ & $219(20.7)$ & $200(29.5)$ & $250(23.6)$ \\
\hline & $25-29.9 \mathrm{~kg} / \mathrm{m}^{2}$ & $402(30.9)$ & $376(27.2)$ & 439 (33.8) & $418(30.2)$ \\
\hline & $\geq 30^{\mathrm{b}} \mathrm{kg} / \mathrm{m}^{2}$ & $376(35.1)$ & $216(32.7)$ & $467(43.6)$ & $258(39)$ \\
\hline \multirow[t]{2}{*}{ Physical exercise ${ }^{c, d}$} & $0-3$ days $^{\mathrm{a}, \mathrm{b}}$ & $535(40.1)$ & $416(34.8)$ & $611(45.8)$ & $46 \mid(38.6)$ \\
\hline & 4-7 days ${ }^{\mathrm{a}, \mathrm{b}}$ & $574(27.3)$ & $505(22.5)$ & $666(31.6)$ & $580(25.8)$ \\
\hline \multirow[t]{3}{*}{ Tobacco use $e^{c, d}$} & Current smoker ${ }^{\mathrm{a}, \mathrm{b}}$ & $140(29.4)$ & $102(20.4)$ & $156(32.7)$ & $124(24.8)$ \\
\hline & Ex-smoker ${ }^{\mathrm{a}, \mathrm{b}}$ & $230(23.4)$ & $197(2 \mid .4)$ & $313(31.9)$ & $247(26.8)$ \\
\hline & Never $^{\mathrm{a}, \mathrm{b}}$ & $704(38)$ & $586(30.8)$ & $759(40.9)$ & $632(33.2)$ \\
\hline \multirow[t]{2}{*}{ Alcohol consumption ${ }^{c, d}$} & $\mathrm{No}^{\mathrm{a}-\mathrm{c}}$ & 871 (35.8) & $640(31.4)$ & $990(40.7)$ & $680(33.4)$ \\
\hline & Yes & $238(23.6)$ & $28 \mid(20)$ & $287(28.5)$ & $36 \mid(25.7)$ \\
\hline \multirow[t]{3}{*}{ Pain intensity ${ }^{c, d}$} & Light & $158(26.1)$ & $143(22.6)$ & $185(30.5)$ & $184(29.1)$ \\
\hline & Moderate & 347 (43.9) & $311(43.7)$ & $389(49.2)$ & $346(48.6)$ \\
\hline & Severe/extreme & $428(58.8)$ & $283(57.1)$ & $487(66.9)$ & $309(62.3)$ \\
\hline \multirow[t]{2}{*}{ Use of pain medication ${ }^{c, d}$} & $\mathrm{No}^{\mathrm{a}}$ & $280(\mid 5.6)$ & $306(14.5)$ & $356(19.9)$ & $350(16.5)$ \\
\hline & $Y_{e s}^{a, b}$ & $829(50.3)$ & $615(46.4)$ & 921 (55.9) & 691 (52.2) \\
\hline Total $\left.\right|^{a-c}$ & & $\mathrm{I}, 109(32.2)$ & $921(26.8)$ & $1,277(37.1)$ & $\mathrm{I}, 04 \mathrm{I}(30.3)$ \\
\hline
\end{tabular}

Notes: a Significant differences $(p<0.05)$ between diabetes suffers and non-diabetes sufferers for neck pain. ${ }^{b}$ Significant differences $(p<0.05)$ between diabetes suffers and nondiabetes sufferers for low back pain. Comparisons conducted using conditional logistic regression. SSignificant association $(p<0.05)$ between the variable and neck pain among diabetes sufferers. ${ }^{~}$ Significant association $(p<0.05)$ between the variable and low back pain among diabetes sufferers. Comparisons were conducted using the chi-square test. Abbreviation: NA, not applicable. 
significantly higher prevalence for all categories of physical exercise, tobacco use, and lack of alcohol consumption.

The prevalence of LBP was significantly higher among DM sufferers with a BMI $\geq 30 \mathrm{~kg} / \mathrm{m}^{2}$ than among non-DM sufferers with obesity (43.6\% vs 39\%).

Among those who had used prescription pain medication in the last 2 weeks, people with DM had more NP (50.3\% vs $46.4 \%, p<0.05)$ and LBP $(55.9 \%$ vs $52.2 \%, p<0.05)$ than people without DM.

The results of the multivariable model to assess the association between DM and pain using multivariable conditional logistic regression showed that, after controlling for possible confounders and discarding interactions, DM was associated with a $1.19(95 \%$ CI 1.04-1.36) higher risk of NP and a 1.20 (95\% CI 1.06-1.35) higher risk of LBP.

The factors associated with NP and LBP among DM sufferers are shown in Table 3.

Female sex was associated with a higher probability of reporting NP (OR 1.77; 95\% CI 1.45-2.16). Those with a "Fair/poor/very poor" self-rated health had 1.56 (95\% CI 1.24-1.97) and 1.55 (95\% CI 1.24-1.95) higher risks of NP and LBP, respectively, than those in the "Very good/good" category. Having a respiratory disease was associated with LBP, and the presence of a mental disorder increased the probability of this pain.
Among diabetic subjects, those with concomitant obesity had a $50 \%$ higher prevalence of LBP than those with a BMI $<25 \mathrm{~kg} / \mathrm{m}^{2}$ (OR 1.50; 95\% CI 1.17-1.92).

More frequent physical activity was associated with a lower self-reported LBP (OR 0.62 95\% CI 0.42-0.89). The use of pain medication over the last 2 weeks increased the risk of reporting any pain localization two or more times.

As can be seen in Table 3, the year of the survey is not significant in the multivariable analysis for any of the pains studied.

Finally, a very high and significant association was found between NP and LBP among DM sufferers; those with any of these two pains had a 8-fold higher probability of suffering from another pain than those who did not have any of them.

\section{Discussion}

The main result of our investigation is that the prevalence of NP and LBP was significantly higher among those with DM than their age- and sex-matched non-diabetic controls after controlling for sociodemographic and health-related variables. Furthermore, diabetic subjects reported high intensities of pain and frequent use of prescription pain medication.

Comparing the prevalence estimations for LBP and NP is difficult because they are self-reported, and the questions

Table 3 Factors associated with neck pain and low back pain among those with diabetes

\begin{tabular}{|c|c|c|c|}
\hline \multirow[t]{2}{*}{ Variable } & \multirow[t]{2}{*}{ Category } & \multirow{2}{*}{$\frac{\text { Neck pain }}{\text { OR (95\% CI) }}$} & \multirow{2}{*}{$\begin{array}{l}\text { Low back pain } \\
\text { OR (95\% CI) }\end{array}$} \\
\hline & & & \\
\hline \multirow[t]{2}{*}{ Sex } & Male & I & NS \\
\hline & Female & $1.77(1.45-2.16)$ & NS \\
\hline \multirow[t]{2}{*}{ Self-rated health } & Very good/good & $\mathrm{I}$ & I \\
\hline & Fair/poor/very poor & $1.56(1.24-1.97)$ & $1.55(1.24-1.95)$ \\
\hline \multirow[t]{2}{*}{ Respiratory disease } & No & NS & I \\
\hline & Yes & NS & $1.34(1.06-1.70)$ \\
\hline \multirow[t]{2}{*}{ Mental disorder } & No & I & I \\
\hline & Yes & $1.30(1.05-1.60)$ & $1.66(1.33-2.08)$ \\
\hline \multirow[t]{3}{*}{ Body mass index, $\mathrm{kg} / \mathrm{m}^{2}$} & $<25$ & NS & I \\
\hline & $25-29.9$ & NS & I.I $3(0.89-1.44)$ \\
\hline & $\geq 30$ & NS & $1.50(1.17-1.92)$ \\
\hline \multirow[t]{2}{*}{ Physical exercise } & $0-3$ days & NS & I \\
\hline & 4-7 days & NS & $0.62(0.42-0.89)$ \\
\hline \multirow[t]{2}{*}{ Use of pain medication } & No & I & I \\
\hline & Yes & $2.00(1.63-2.44)$ & 2.05 (1.67-2.52) \\
\hline \multirow[t]{2}{*}{ Neck pain } & No & NA & I \\
\hline & Yes & NA & $8.46(6.95-10.29)$ \\
\hline \multirow[t]{2}{*}{ Low back pain } & No & I & NA \\
\hline & Yes & $8.30(6.91-9.96)$ & NA \\
\hline \multirow[t]{2}{*}{ EHSS } & 2009 & 1 & I \\
\hline & 2014 & $0.97(0.93-1.03)$ & $1.00(0.96-1.05)$ \\
\hline
\end{tabular}

Notes: OR estimated using multivariable unconditional logistic regression. Only significant variables are shown in the table.

Abbreviations: EHSS, European Health Interview Surveys for Spain; NA, not applicable; NS, not significant. 
used to collect information about pain and the characteristics of the study populations differ between investigations.

In the United States, using the National Health and Nutrition Examination Survey for years 2010-2011, it was found that the prevalence of chronic LBP was $19.8 \%$ in adults (aged 20-69 years) with DM vs $12.9 \%$ in adults without DM. These authors defined chronic LBP as a self-reported history of LBP for "3 months in a row". After adjustments for age and LBP's known risk factors, the association remained significant. ${ }^{12}$

The results of the EpiReumaPt, a national cross-sectional study conducted in Portugal from September 2011 to December 2013, showed a prevalence of active chronic LBP of $18.6 \%$ among those with self-reported DM vs $6.8 \%$ for those without it. Active chronic LBP was considered if it was present on the day of the interview and for more than 90 days. ${ }^{14}$

Eivazi and $\mathrm{Abadi}^{13}$ interviewed 317 diabetic patients in a single clinic in Iran with the same question used in our investigation and found a 1 -year prevalence of LBP of $63.4 \%$, which was $47 \%$ in a non-diabetic control group ( $p<0.009)$.

Among Danish patients with type $2 \mathrm{DM}$, the prevalence of LBP in the last 14 days was $60 \%$ compared with $30 \%$ in the age-, sex-, and region-matched general population $(p<0.001) .{ }^{15}$

Beyond the methodological issues, our result agrees with the existing literature on the negative impact of type $2 \mathrm{DM}$ on LBP. ${ }^{12-15}$

Regarding NP, previous studies on the relationship between NP and DM have yielded conflicting results. ${ }^{12,16,17}$ Our results agree with Molsted et al, ${ }^{15}$ who compared 951 patients with type $2 \mathrm{DM}$ with data for 2,923 matched subjects from the general population and observed that patients with type 2 DM had a significantly higher prevalence of musculoskeletal pain in all areas of the body, including cervical pain. In the US, using the 2002 National Health Interview Survey, it was found that the 3-month prevalence rate of back and/or NP had a significant association with concomitant LBP and NP for people with DM. ${ }^{16}$

However, in the Johnston County Osteoarthritis Project, neck and shoulder symptoms were associated with DM; however, the association between DM and NP was not significant after full adjustment. ${ }^{17}$

The severe intensity of pain and frequent need for pain medication have been reported among DM sufferers. ${ }^{9}$ In US diabetic patients with chronic pain, $60 \%$ in the back, almost one-third indicated that their pain was severe or very severe during the past 4 weeks, and $78 \%$ reported that they used pain medication on either a regular or occasional basis. ${ }^{9}$ In our population, $34.3 \%$ of DM sufferers had intense or extreme pain in the last 4 weeks and $47.9 \%$ had taken prescription pain medication. However, among those with NP and LBP, the proportions reporting severe or intense pain increased to $58.8 \%$ and $66.9 \%$, respectively. The intensity of pain is a relevant issue given that diabetic patients with severe or very severe pain, compared with mild or moderate pain, had worse DM self-management, including exercise, and greater difficulty taking DM medications. ${ }^{9}$

Identifying the factors associated with NP and LBP is important because health services can focus on these patients and insist on prevention strategies that try to modify unhealthy lifestyles that can otherwise worsen these pains.

Female sex has been associated with NP in the general population and among DM sufferers..$^{5,15,16,22}$ In Spain, the results of national health surveys showed that women aged 16 years or over had 2.03 (95\% CI 1.80-2.27) times higher prevalence of NP than men. ${ }^{5}$ Molsted et $\mathrm{al}^{15}$ found that the proportion of diabetic women with neck or shoulder pain was $59 \%$ compared to only $44 \%$ among diabetic men.

In our investigation, worse self-rated health was associated with a higher prevalence of both pain localizations. This is an expected result because these two pains have important effects on the quality of life of people with and without DM, which has been described by other authors. ${ }^{2-6,9,16,22,23}$

Suffering from concomitant respiratory diseases increased the probability of reporting LBP 1.34-fold among DM sufferers. The higher prevalence of LBP among people suffering from asthma and COPD compared to those without these conditions has been described in the general population. ${ }^{11,16,24}$ Furthermore, recent investigators have described the association between comorbidities and pain in COPD. ${ }^{24,25}$

As with other authors, we found that DM sufferers who reported a mental disorder also had significantly higher probabilities of pain. ${ }^{9}$ Several population surveys have shown a strong association between NP and LBP and depression and/ or anxiety. ${ }^{5,26,27}$

The multivariable model for LBP among diabetic subjects yielded a significant association with a higher body mass index and physical inactivity, which have been previously reported as risk factors for LBP in studies conducted in either general and diabetic populations..$^{5,69,12,14-16,28,29}$ Molsted et al ${ }^{15}$ found that, in both sexes, BMI was associated with LBP and pain in the knee, hip, arm, and hand, among diabetic patients. Physical inactivity was associated with low-back pain.

Several causes may explain the association between diabetes and NP and LBP. ${ }^{7,8,31-38}$ Beside the fact that obese individuals experience greater motion forces of the spinal segments, diabetes itself creates an environment that may 
negatively affect IVD health, resulting in alterations in the structural composition of the disc which in turn may alter the mechanical properties of the tissues and lead to increase susceptibility to disc prolapse and consequent mechanical back pain. ${ }^{7,8,31-36}$

Recently, Fields et al attempted to isolate the effects of diabetes by comparing obese Sprague-Dawley rats to diabetic obese T2DM rats while using lean rats as an additional control. The diabetic rats alone had an elevated advanced glycation end products (AGE) concentration, which was associated with lower glycosaminoglycan and water content of discs. ${ }^{30}$ Several authors have reported a significant increase in AGE and rate of tissue cross-linking in the IVD of rats with increased $\mathrm{HbA} 1 \mathrm{c}$ and high glucose levels that result in the degeneration of the IVD. ${ }^{7,31-34}$ Increased cross-linking leads to stiffness and brittleness, resulting in an IVD that may be more susceptible to mechanical damage and has lower shockabsorbing properties. ${ }^{31-34}$ Furthermore, the well-demonstrated microangiopathy associated with diabetes diminishes the flow of nutrients and oxygen to IVD from capillaries at their margins and impairs IVD cell viability. ${ }^{33,35}$

Diabetic patients have been shown to have significantly decreased disc height, in comparison to their non-diabetic counterparts, and T2DM has been linked to lumbar spinal stenosis. ${ }^{8,36}$ In addition, DM may contribute to osteopenia, osteoarthritis, hyperostosis, as well as vasoregulation abnormalities, such as in Charcot joint formation. ${ }^{18}$ These changes may alter the biomechanics of the spine and contribute to back pain. ${ }^{18}$

Some, but not all, investigations have suggested that pharmacologic treatment for DM with DPP-4 inhibitors may result in an increased risk of severe joint pain. ${ }^{37}$ However, more studies to better clarify the association between DPP-4 inhibitors and arthritis/arthralgia are necessary. ${ }^{37}$

Our results have implications regarding the management of patients with DM. The current evidence suggests that exercise alone or in combination with education is effective for preventing LBP. ${ }^{38}$ Among diabetic patients, additional benefits of physical activity include improvement in the pain, function, and quality of life; decreased systemic complications of DM, and less negative structural changes in the IVDs and fat infiltration in the paraspinal muscles. ${ }^{39-41}$

At the same time, giving advice about weight reduction methods or consulting with a dietician is a good approach for reducing LBP in diabetic subjects.

Specific interventions include, among others, therapeutic exercise, ergonomic adaptation of this population to a work environment at home or workplace, and health education to increase their awareness about back problems and how to prevent and treat them. ${ }^{13}$

The strength of this study is the large unselected population with a matched design to avoid the confounding effect of age and sex and the potential to analyze an important number of sociodemographic characteristics, comorbidities, and lifestyle variables that are not available in the clinical setting.

However, there are several limitations that should be noted. First, the causality issue cannot be properly addressed because of the study design. Second, self-reporting is the only source for assessing information on NP and LBP, but under-reporting or over-reporting may appear from recall, information, or social desirability biases. ${ }^{12}$

Third, in the multivariate analyses, we were able to adjust for a large number of potential confounding factors, but the possibility of residual confounding by unrecognized factors cannot be ruled out. For example, injury at neck or low back is a major cause of NP and LBP, but unfortunately the EHSS does not collect information on these injuries. Fourth, the characteristics of DM are not collected in the EHSS, including the DM type, duration, treatment, and chronic complications.

Fifth, the validity of the self-reported conditions included in the EHSS has not been evaluated. However, for DM, a study conducted in Spain reported specificities $>95 \%$ and sensitivities $>70 \%$ using medical records as the gold standard. ${ }^{42}$

Finally, the response rates for the EHSS 2009 and 2014 were $\sim 65 \%$ and $61 \%$, respectively, such that the existence of a selection bias must be considered. ${ }^{19,20}$

\section{Conclusion}

The prevalence and intensity of NP and LBP are high among those with DM, and they significantly affect these patients more than their age- and sex-matched non-diabetic controls after controlling for possible confounders. Among female diabetic subjects, suffering concomitant mental or respiratory disorders, being obese, and physical inactivity are associated with suffering from these pains. Specific preventive and educational strategies must be implemented to reduce the incidence, prevalence, and consequences of these pains in the diabetic population.

\section{Acknowledgments}

This study is part of research funded by the FIS (Fondo de Investigaciones Sanitarias-Health Research Fund, grant no. PI16/00564, Instituto de Salud Carlos III) and co-financed by the European Union through the Fondo Europeo de 
Desarrollo Regional (Una manera de hacer Europa) and by the Grupo de Excelencia Investigadora URJC-Banco Santander N³0VCPIGI03: Investigación Traslacional en el Proceso de Salud - Enfermedad.

\section{Disclosure}

The authors report no conflicts of interest in this work.

\section{References}

1. GBD 2015 Disease and Injury Incidence and Prevalence Collaborators. Global, regional, and national incidence, prevalence, and years lived with disability for 310 diseases and injuries, 1990-2015: a systematic analysis for the Global Burden of Disease Study 2015. Lancet. 2016;388(10053):1545-1602.

2. Breivik H, Collett B, Ventafridda V, Cohen R, Gallacher D. Survey of chronic pain in Europe: prevalence, impact on daily life, and treatment. Eur J Pain. 2006;10(4):287-333.

3. Eumusc.net Musculoskeletal Health in Europe Report v5.0. Available from: http://www.eumusc.net/myUploadData/files/Musculoskeletal $\% 20$ Health\%20in\%20Europe\%20Report\%20v5.pdf. Accessed March 17, 2017.

4. Raciborski F, Gasik R, Kłak A. Disorders of the spine. A major health and social problem. Reumatologia. 2016;54(4):196-200.

5. Palacios-Ceña D, Alonso-Blanco C, Hernández-Barrera V, CarrascoGarrido P, Jiménez-García R, Fernández-de-las-Peñas C. Prevalence of neck and low back pain in community-dwelling adults in Spain: an updated population-based national study (2009/10-2011/12). Eur Spine J. 2015;24(3):482-492.

6. Fernández-de-Las-Peñas C, Alonso-Blanco C, Hernández-Barrera V, Palacios-Ceña D, Jiménez-García R, Carrasco-Garrido P. Has the prevalence of neck pain and low back pain changed over the last 5 years? A population-based national study in Spain. Spine J. 2013;13(9):1069-1076.

7. Won HY, Park JB, Park EY, Riew KD. Effect of hyperglycemia on apoptosis of notochordal cells and intervertebral disc degeneration in diabetic rats. J Neurosurg Spine. 2009;11(6):741-748.

8. Anekstein Y, Smorgick Y, Lotan R, et al. Diabetes mellitus as a risk factor for the development of lumbar spinal stenosis. Isr Med Assoc J. 2010;12(1):16-20.

9. Krein SL, Heisler M, Piette JD, Makki F, Kerr EA. The effect of chronic pain on diabetes patients' self-management. Diabetes Care. 2005;28(1):65-70.

10. Rinaldo L, McCutcheon BA, Gilder H, et al. 341 Diabetes mellitus and back pain: markers of diabetes disease progression are associated with chronic back pain. Neurosurgery. 2016;63 Suppl 1:200.

11. Ritzwoller DP, Crounse L, Shetterly S, Rublee D. The association of comorbidities, utilization and costs for patients identified with low back pain. BMC Musculoskelet Disord. 2006;7:72.

12. Hassoon A, Bydon M, Kerezoudis P, Maloney PR, Rinaldo L, Yeh HC. Chronic low-back pain in adult with diabetes: NHANES 2009-2010. J Diabetes Complications. 2017;31(1):38-42.

13. Eivazi M, Abadi L. Low back pain in diabetes mellitus and importance of preventive approach. Health Promot Perspect. 2012;2(1):80-88.

14. Gouveia N, Rodrigues A, Eusébio M, et al. Prevalence and social burden of active chronic low back pain in the adult Portuguese population: results from a national survey. Rheumatol Int. 2016;36(2):183-197.

15. Molsted S, Tribler J, Snorgaard O. Musculoskeletal pain in patients with type 2 diabetes. Diabetes Res Clin Pract. 2012;96(2):135-140.

16. Strine TW, Hootman JM. US national prevalence and correlates of low back and neck pain among adults. Arthritis Rheum. 2007;57(4):656-665.

17. Wright AR, Shi XA, Busby-Whitehead J, Jordan JM, Nelson AE. The prevalence of neck and shoulder symptoms and associations with comorbidities and disability: the Johnston County Osteoarthritis Project. Myopain. 2015;23(1-2):34-44.
18. Lebiedz-Odrobina D, Kay J. Rheumatic manifestations of diabetes mellitus. Rheum Dis Clin North Am. 2010;36(4):681-699.

19. Instituto Nacional de Estadistica. European Health Interview Survey for Spain, 2009. Available from: http://www.ine.es/metodologia/t15/ t153042009.pdf. Accessed July 20, 2017.

20. Instituto Nacional de Estadistica. European Health Interview Survey for Spain, 2014. Available from: http://www.ine.es/metodologia/t15/ t153042014.pdf. Accessed July 20, 2017.

21. European Commission. Eurostat: The European Health Interview Survey. Available from: http://ec.europa.eu/eurostat/web/microdata/ european-health-interview-survey. Accessed July 20, 2017.

22. Stranjalis G, Kalamatianos T, Stavrinou LC, Tsamandouraki K, Alamanos Y. Neck pain in a sample of Greek urban population (fifteen to sixty-five years): analysis according to personal and socioeconomic characteristics. Spine (Phila Pa 1976). 2011;36(16): E1098-E1104.

23. Mäntyselkä PT, Turunen JH, Ahonen RS, Kumpusalo EA. Chronic pain and poor self-rated health. JAMA. 2003;290(18):2435-2442.

24. van Dam van Isselt EF, Groenewegen-Sipkema KH, Spruit-van Eijk M, et al. Pain in patients with COPD: a systematic review and meta-analysis. BMJ Open. 2014;4(9):e005898.

25. Chen YW, Camp PG, Coxson HO, et al. Comorbidities that cause pain and the contributors to pain in individuals with chronic obstructive pulmonary disease. Arch Phys Med Rehabil. 2017;98(8): $1535-1543$.

26. Demyttenaere K, Bruffaerts R, Lee S, et al. Mental disorders among persons with chronic back or neck pain: results from the World Mental Health Surveys. Pain. 2007;129(3):332-342.

27. Blozik E, Laptinskaya D, Herrmann-Lingen C, et al. Depression and anxiety as major determinant of neck pain: a cross-sectional study in general practice. BMC Musculoskelet Disord. 2009;10:13.

28. Shiri R, Karppinen J, Leino-Arjas P, Solovieva S, Viikari-Juntura E. The association between obesity and low back pain: a meta-analysis. Am J Epidemiol. 2010;171(2):135-154.

29. Manchikanti L, Singh V, Falco FJ, Benyamin RM, Hirsch JA. Epidemiology of low back pain in adults. Neuromodulation. 2014;17 Suppl 2:3-10.

30. Fields AJ, Berg-Johansen B, Metz LN, et al. Alterations in intervertebral disc composition, matrix homeostasis and biomechanical behavior in the UCD-T2DM rat model of type 2 diabetes. $J$ Orthop Res. 2015;33(5):738-746.

31. Sivan SS, Tsitron E, Wachtel E, et al. Age-related accumulation of pentosidine in aggrecan and collagen from normal and degenerate human intervertebral discs. Biochem J. 2006;399(1):29-35.

32. Metz LN, Lovell AF, Graham J, Liebenberg E, Havel P, Lotz JC. Does diabetes cause the intervertebral disc to degenerate? Spine J. 2012;(12 Suppl):S74-S75.

33. Kong CG, Park JB, Kim MS, Park EY. High glucose accelerates autophagy in adult rat intervertebral disc cells. Asian Spine J. 2014;8(5):543-548.

34. Wagner DR, Reiser KM, Lotz JC. Glycation increases human annulus fibrosus stiffness in both experimental measurements and theoretical predictions. J Biomech. 2006;39(6):1021-1029.

35. Grunhagen T, Shirazi-Adl A, Fairbank JC, Urban JP. Intervertebral disk nutrition: a review of factors influencing concentrations of nutrients and metabolites. Orthop Clin North Am. 2011;42(4):465-477, vii.

36. Agius R, Galea R, Fava S. Bone mineral density and intervertebral disc height in type 2 diabetes. J Diabetes Complications. 2016;30(4): 644-650.

37. Mascolo A, Rafaniello C, Sportiello L, et al. Dipeptidyl peptidase (DPP)-4 inhibitor-induced arthritis/arthralgia: a review of clinical cases. Drug Saf. 2016;39(5):401-407.

38. Steffens D, Maher CG, Pereira LS, et al. Prevention of low back pain: a systematic review and meta-analysis. JAMA Intern Med. 2016;176(2): 199-208. 
39. Natour J, Cazotti Lde A, Ribeiro LH, Baptista AS, Jones A. Pilates improves pain, function and quality of life in patients with chronic low back pain: a randomized controlled trial. Clin Rehabil. 2015;29(1):59-68.

40. Blomster JI, Chow CK, Zoungas S, et al. The influence of physical activity on vascular complications and mortality in patients with type 2 diabetes mellitus. Diabetes Obes Metab. 2013;15(11): 1008-1012.
41. Teichtahl AJ, Urquhart DM, Wang Y, et al. Physical inactivity is associated with narrower lumbar intervertebral discs, high fat content of paraspinal muscles and low back pain and disability. Arthritis Res Ther 2015; 17:114.

42. Huerta JM, Tormo MJ, Egea-Caparrós JM, Ortolá-Devesa JB, Navarro C. Accuracy of self-reported diabetes, hypertension and hyperlipidemia in the adult Spanish population. DINO study findings. Rev Esp Cardiol. 2009;62(2):143-152. Spanish [with English abstract].

\section{Publish your work in this journal}

The Journal of Pain Research is an international, peer reviewed, open access, online journal that welcomes laboratory and clinical findings in the fields of pain research and the prevention and management of pain. Original research, reviews, symposium reports, hypothesis formation and commentaries are all considered for publication.

\section{Dovepress}

The manuscript management system is completely online and includes a very quick and fair peer-review system, which is all easy to use. Visit http://www.dovepress.com/testimonials.php to read real quotes from published authors. 